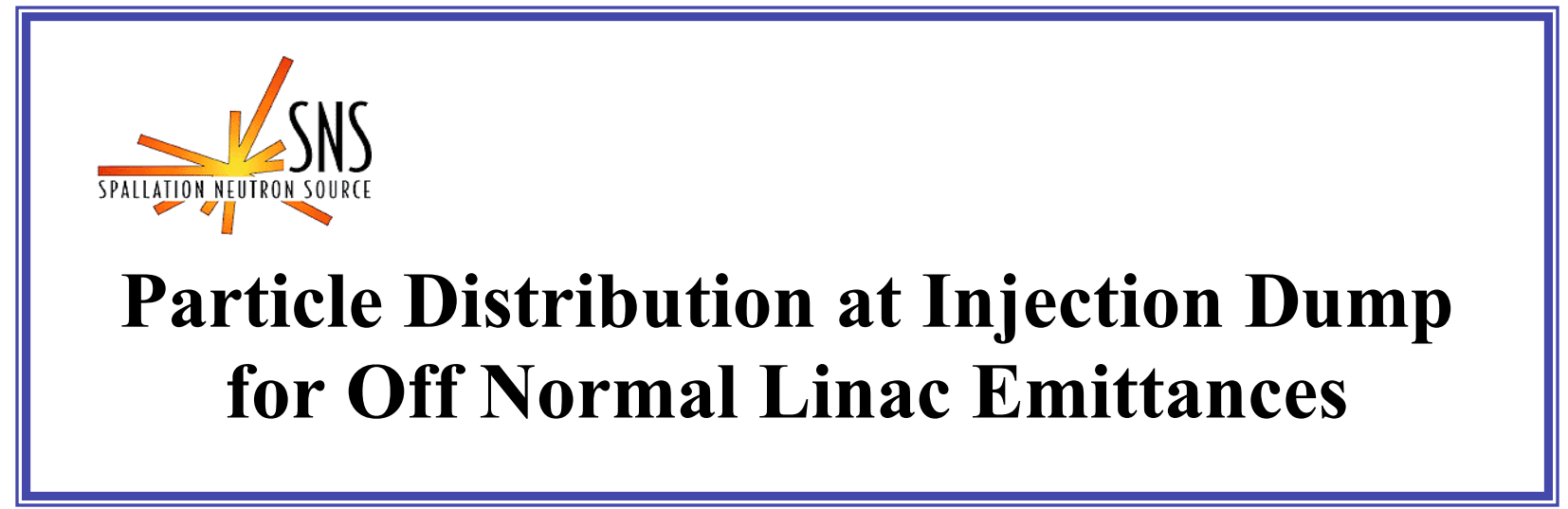

BNL/SNS TECHNICAL NOTE

NO. 133

D. Raparia

April 1, 2004

COLLIDER-ACCELERATOR DEPARTMENT

BROOKHAVEN NATIONAL LABORATORY

UPTON, NEW YORK 11973 


\title{
Particle Distribution at Injection Dump for Off Normal Linac Emittances
}

\author{
Deepak Raparia
}

March 29, 2004

\section{Introduction}

Target group calculation shows that the present design of the injection dump will not satisfy the requirement in the SNS parameter list for the injection dump (see Table I). Specially, the requirement that beam center can be off center by $\pm 5.0 \mathrm{~cm}$ for $200 \mathrm{~kW}$ of beam power. Simulations were carried out to ensure beam size and centroid off set for off normal emittance from the linac

Table I: Injection Beam Dump Specification from the Parameters List.

\begin{tabular}{|l|l|}
\hline Parameter & \\
\hline Power & $150 \mathrm{kWatt} \equiv$ \\
\hline Beam radius & $100 \mathrm{~mm}(99 \%$ of beam energy) \\
\hline Centroid displacement & $\pm 50 \mathrm{~mm}$ \\
\hline Mac particle/current density & $5.0 \times 10^{15} \mathrm{PPP} / \mathrm{m}^{2}=0.048 \mathrm{~A} / \mathrm{m}^{2}$ \\
\hline Operation hours per year & 5000 \\
\hline
\end{tabular}

\section{Injection Dump Optics}

Injection beam dump is designed to absorb $200 \mathrm{~kW}$ of beam power and requires that $99 \%$ of the beam should lie in $200 \mathrm{~mm}$ diameter circle. It will collect un-stripped $\mathrm{H}^{-}$and partially stripped $\mathrm{H}^{0}$ ions. Figure 1 shows the layout of the injection region.

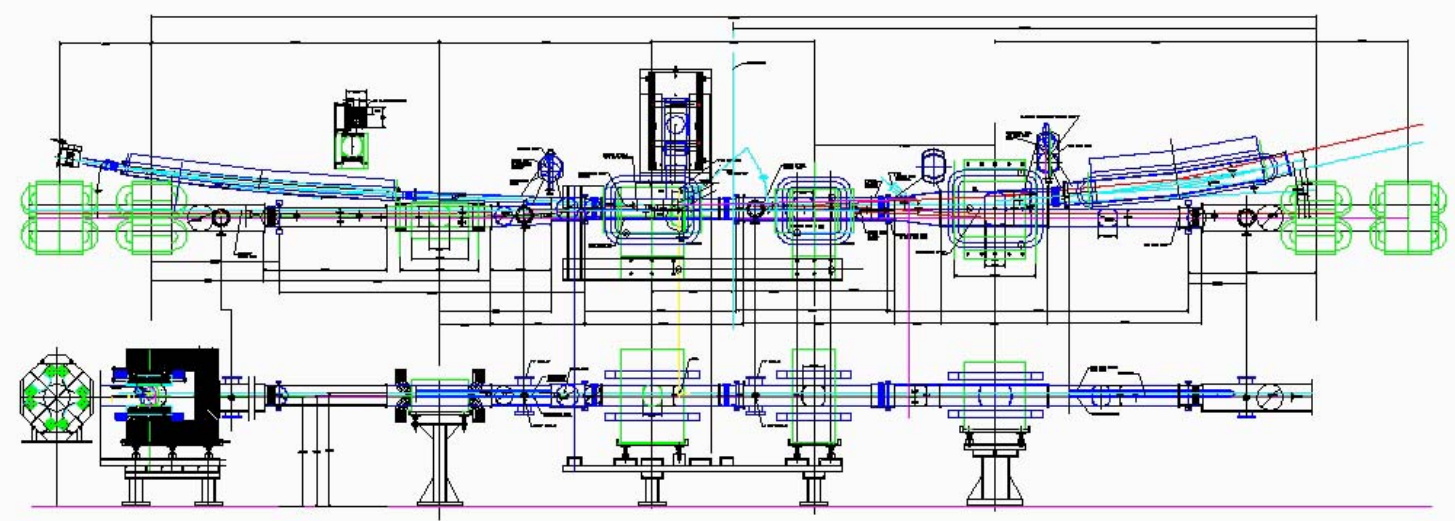

Figure 1: Layout of the injection region. 
$\mathrm{H}^{-}$ions are injected into the ring via charge exchange through carbon foil of thickness ranging $200-400 \mu \mathrm{g} / \mathrm{cm}^{2}$. Final foil thickness will depend on the R\&D on the diamond foil carried out at ORNL. The striping efficiency at $1 \mathrm{GeV}$ is shown in fig 2.

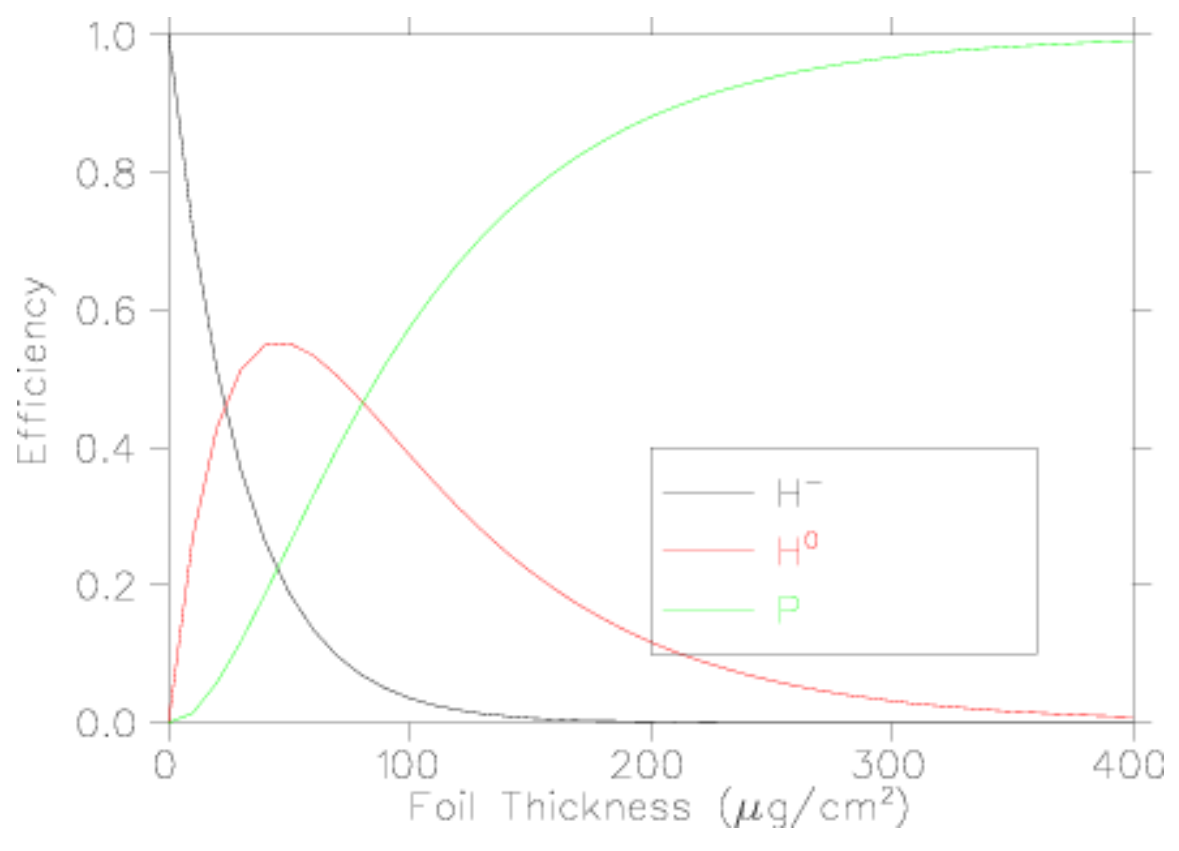

Fig 2. Stripping efficiency for $1 \mathrm{GeV} \mathrm{H}^{-}$ions.

$\mathrm{H}^{-}$ions which have missed the foil will emerge from the injection bump magnet \# 2 as $4.2 \mathrm{mrad}$ toward left, $\mathrm{H}^{0}$ will go straight and proton will bend $4.2 \mathrm{mrad}$ right. The injection bump magnet \# 3 will bend further $\mathrm{H}^{-}$ions by $42 \mathrm{mrad}$ while $\mathrm{H}^{0}$ ions will go straight. There will be a thick foil $\left(\sim 10 \mathrm{mg} / \mathrm{cm}^{2}\right)$ before the injection bump magnet $\# 4$, which will convert $\mathrm{H}^{-}$and $\mathrm{H}^{0}$ ions to proton by stripping two and one electrons respectively. After injection bump magnet \#4 both trajectory goes through an injection dump gradient magnet and finally though an $\mathrm{x}$-defocusing quadrupole magnet. The optics is such that that the both trajectories coincide at the injection dump [1]. Figure 3 shows the $\mathrm{H}^{0}$ centroid displacement with respect to the central ray (average of $\mathrm{H}^{0}$ and $\mathrm{H}^{-}$ trajectories). $\mathrm{H}^{-}$trajectory will be just mirror of the $\mathrm{H}^{0}$ trajectories in Figure 3. Figure 4 show $\beta$ and $\eta$ functions for the injection beam dump beam line. 


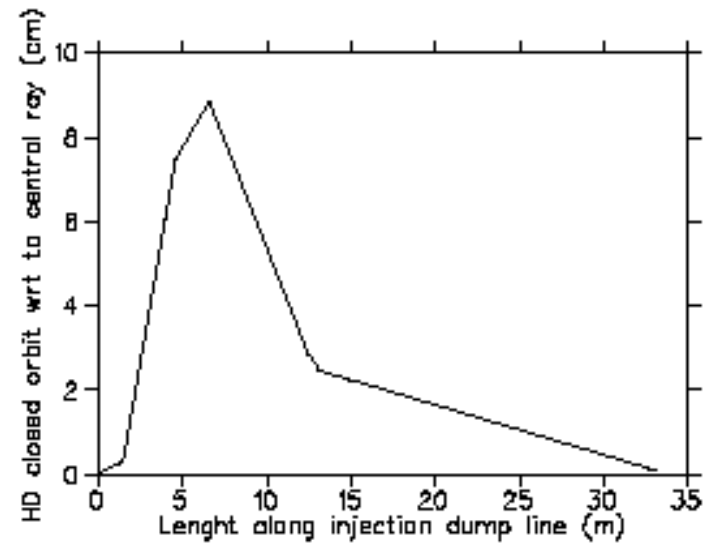

Figure $3: \mathrm{H}^{0}$ trajectory displacement with respect to the central ray.

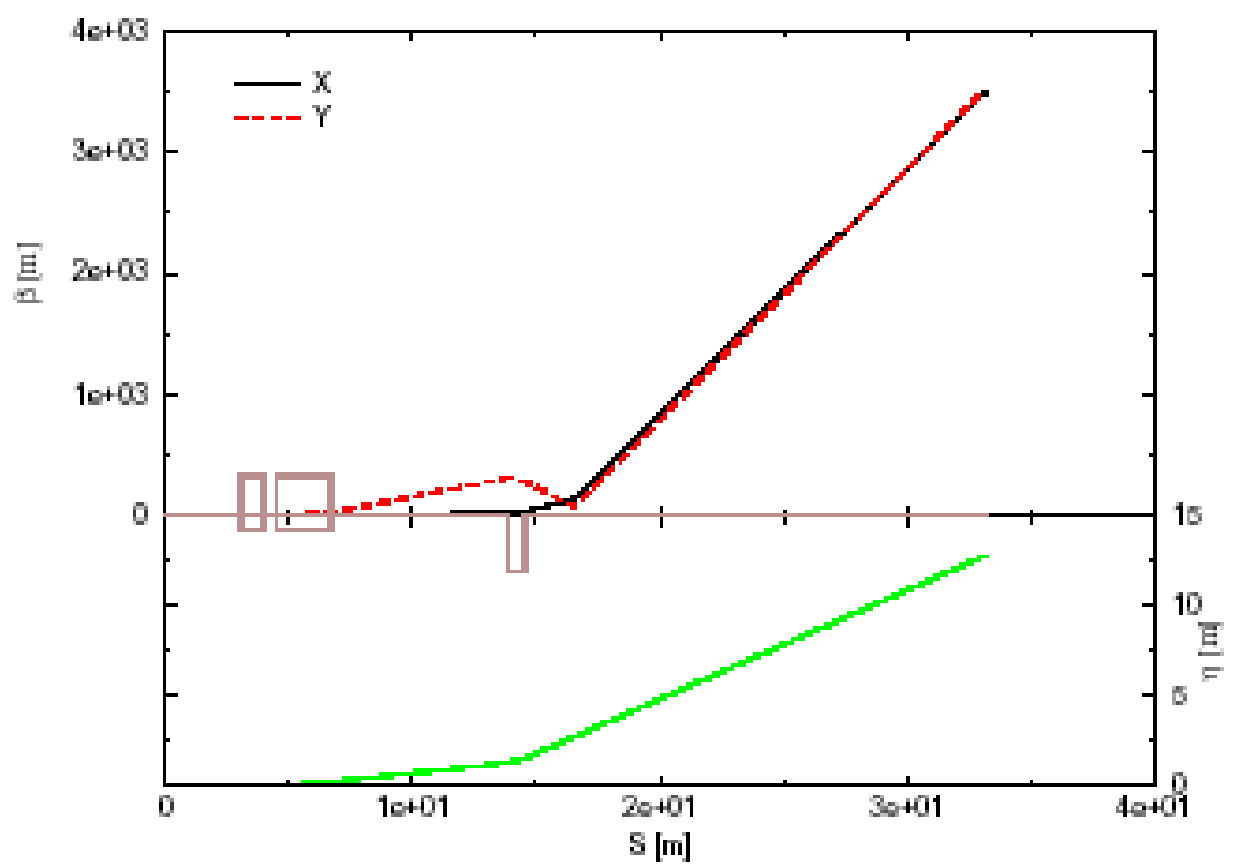

Figure 4: $\beta$ and $\eta$ function in the injection dump line.

The design linac emittance is $0.5 \pi \mathrm{mm} \operatorname{mrad}$ (rms, nor). If the linac emittance is bigger than the design, the beam size at the target will grow as the square root of the emittance, Table II shows TRANSPORT calculations for the beam size at the injection dump for different injection-dump quadrupole settings $(\mathrm{S})$ and three different emittances. For run numbers SN 1-5, matched-injections were assumed, which means that as the emittance grows the foil size also grows accordingly. For run numbers, SN 6-9, mismatched injections into the ring were assumed, so that the foil size remains the same as the emittance grows. Table III shows the required gradient in the last quads in the HEBT to achieve mismatch injection. Mismatch injections into the ring were studied [2] and the mismatched schemes considered here will satisfy the conditions required for the mismatch injection into the ring. 
Table II: Beam size at the Injection dump for various linac emittances.

$\mathrm{delp} / \mathrm{p} \quad 0.0002$

SN

Centroid (cm) $\beta_{X}(m) \beta_{Y}(m) \eta_{X}(m) S(T / m)$

$0 \quad 3423 \quad 2425 \quad 122.6116$

$\pm 1.41 \quad 3137 \quad 1759 \quad 11.42 .4116$

$\pm 2.81 \quad 2864 \quad 1197 \quad 10.82 .2116$

$\pm 4.2 \quad 2606 \quad 740 \quad 10.12 .0116$

$\pm 5.59 \quad 2361 \quad 391 \quad 9.51 .8116$

$\begin{array}{rrrr}0 & 1777 & 2212 & 122.6116\end{array}$

$\pm 2.81 \quad 1494 \quad 1073 \quad 10.82 .2116$

6

7

$3^{*} \varepsilon$

8

9
(A) $\varepsilon_{\varepsilon}=0.5 \pi \mathrm{mm} \mathrm{mr}$ (rms, nor) (B) $\varepsilon=1.0 \pi \mathrm{mm} \mathrm{mr}$ (rms, nor) (C) $\varepsilon=1.5 \pi \mathrm{mm} \mathrm{mr}(\mathrm{rms}$, nor)

\begin{tabular}{|c|c|c|c|c|c|c|c|c|}
\hline & & $C D$ & & & $C D$ & $\equiv$ & & $C D$ \\
\hline $\begin{array}{l}\text { Xdia } \\
(\mathrm{mm})\end{array}$ & $\begin{array}{l}\text { Ydia } \\
(\mathrm{mm})\end{array}$ & ${ }^{C D_{\text {NORMAL }}}$ & $\begin{array}{l}\text { Xdia } \\
(\mathrm{mm})\end{array}$ & $\begin{array}{l}\text { Ydia } \\
(\mathrm{mm})\end{array}$ & $C D_{\text {NORMAL }}$ & $\begin{array}{l}D_{\mathrm{Xdia}} \\
(\mathrm{mm})\end{array}$ & $\begin{array}{l}\text { Ydia } \\
(\mathrm{mm})\end{array}$ & $C D_{\text {NORMAL }}$ \\
\hline 185.7521 & 1156.3458 & 1 & 1262.693 & 3221.11 & & 0.5321 .73 & 270.79 & 0.33333 \\
\hline 177.8228 & 8133.1567 & 1.2265 & 251.479 & 9188.31 & 0.613 & 325 & 230.63 & 0.40883 \\
\hline 169.9092 & 2109.8443 & 1.55606 & 240.288 & 8155.34 & $0.77 \varepsilon$ & 294.29 & 190.25 & 0.51869 \\
\hline 162.0755 & 586.36666 & 2.0747 & 7229.209 & 9122.14 & 1.037 & 3735280.72 & 149.59 & 0.69157 \\
\hline 154.2689 & 962.77961 & 2.99863 & 3218.169 & 988.784 & 1.495 & $931 \quad 267.2$ & 108.73 & 0.99954 \\
\hline
\end{tabular}

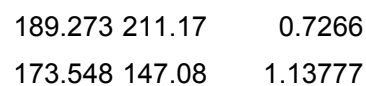

Table III: HEBT Quad Strength (QS) at $1 \mathrm{GeV}$ for Mismatch Injection.

\begin{tabular}{|l|l|l|l|l|l|l|}
\hline Quad \# & $\begin{array}{l}\varepsilon=0.5 \pi \mathrm{mm} \mathrm{mr} \\
(\mathrm{rms}, \mathrm{nor}) \\
\text { QS }(\mathrm{T} / \mathrm{m})\end{array}$ & $\begin{array}{l}\varepsilon=1.0 \pi \mathrm{mm} \mathrm{mr} \\
(\mathrm{rms}, \mathrm{nor}) \\
\mathrm{QS}(\mathrm{T} / \mathrm{m})\end{array}$ & $\begin{array}{l}\varepsilon=1.5 \pi \mathrm{mm} \mathrm{mr} \\
(\mathrm{rms}, \mathrm{nor}) \\
\mathrm{QS}(\mathrm{T} / \mathrm{m})\end{array}$ & $\begin{array}{l}\text { Opeating } \\
\text { I \& V } \\
(\text { for } 1.3 \mathrm{GeV}+10 \%)\end{array}$ & PS Rating & comments \\
\hline $25,27,29,31$, & 3.38761 & 3.43833 & 3.65898 & $351 \mathrm{~A}, 25.5 \mathrm{~V}$ & $390 \mathrm{~A}, 24 \mathrm{~V}$ & ok \\
\hline $26,28,32$ & 3.39917 & 3.30015 & 3.29048 & $350 \mathrm{~A}, 19.7 \mathrm{~V}$ & $390 \mathrm{~A}, 24 \mathrm{~V}$ & ok \\
\hline 30 & 4.25811 & 4.36870 & 4.82094 & $427 \mathrm{~A}, 10.3 \mathrm{~V}$ & $700 \mathrm{~A}, 18 \mathrm{~V}$ & ok \\
\hline 33 & 5.53510 & 6.09161 & 5.83802 & $663 \mathrm{~A}, 15.5 \mathrm{~V}$ & $700 \mathrm{~A}, 18 \mathrm{~V}$ & $-5 \%$ \\
\hline 34 & 5.00592 & 5.69822 & 5.37146 & $610 \mathrm{~A}, 14.1 \mathrm{~V}$ & $700 \mathrm{~A}, 18 \mathrm{~V}$ & ok \\
\hline
\end{tabular}

\section{PARMILA Simulation}

PARMILA was modified to track three species (P, H-, $\left.\mathrm{H}^{0}\right)$ and included multiple and nuclear scattering. Foil will be carbon about $300 \mu \mathrm{g} / \mathrm{cm}^{2}$, about $4 \% \mathrm{H}^{-}$will be partially stripped and about $1-2 \% \mathrm{H}^{-}$ion will miss the foil. PARMILA simulations were carried out for various emittances at the injection foil. These simulations include multiple and nuclear scattering due the both foils. Particle distribution used in these simulations was obtain from end to end simulation at end of HEBT and has 0.365 and $0.319 \pi \mathrm{mm}$ rad (rms, nor) emittances in $\mathrm{x}$ and y plane respectively for 95610 micro-particles. To obtain larger ( 2 or 3 times) emittance for matched cases particle co-ordinates (x, x', y y') were multiplied by square root of emittance factor (2 or 3$)$. In case of mismatched injection only angle coordinates ( $x$ ' and y') were multiplied by the emittance factor ( 2 or 3 ). 
Reference Distribution: For the reference design Gaussin distribution (truncated at three sigma) was used with emittance $\varepsilon=0.5 \pi \mathrm{mm}$ mrad (rms, nor) at the charge exchange foil. Figure $5 \mathrm{~A}$ and $5 \mathrm{~B}$ shows the beam size at foil and at the dump for design emittance $\varepsilon=0.5$ $\pi \mathrm{mm} \mathrm{mrad}$ (rms, nor) and design optics There were about $0.07 \%$ loss in the flight tube. SN: 1A- Figure 6A and 6B shows the beam size at foil and at the dump for design emittance $\varepsilon=0.5 \pi \mathrm{mm} \mathrm{mrad}$ (rms, nor) and design optics There were about $0.3 \%$ loss in the flight tube.

SN: 1B- Figure 7A and 7B shows the particle distribution at the foil and at the dump for $\varepsilon=1.0 \pi \mathrm{mm} \operatorname{mrad}(\mathrm{rms}$, nor) i.e. twice the design emittance and design optics and foil size was increased by $41 \%$ There were about $3.0 \%$ loss in the flight tube.

SN: 1C- Figure: $8 \mathrm{~A}$ and $8 \mathrm{~B}$ shows the particle distribution at the foil and at the dump for $\varepsilon=1.5 \pi \mathrm{mm} \mathrm{mrad}$ (rms, nor) i.e. three times the design emittance and design optics and foil size was increased by $73 \%$ There were about $9.0 \%$ loss in the flight tube.

SN: 7B- Figure 9A and 9B shows the particle distribution at the foil and at the dump for $\varepsilon=1.0 \pi \mathrm{mm}$ mrad (rms, nor) i.e. twice the design emittance and optimize optics and foil size was same as the design i.e. mismatch injection into the ring. There were about $0.3 \%$ loss in the flight tube.

SN: 9C- Figure 10A and 10B shows the particle distribution at the foil and at the dump for $\varepsilon=1.5 \pi \mathrm{mm} \mathrm{mrad}$ (rms, nor) i.e. three times the design emittance and optimize optics and foil size was same as design. There were about $0.5 \%$ loss in the flight tube.

Table IV: Beam loss, particle density and beam size at injection dump.

\begin{tabular}{|c|c|c|c|c|c|c|c|c|}
\hline \multirow[t]{2}{*}{ Run\# } & \multicolumn{5}{|c|}{ Beam Loss } & \multirow{2}{*}{$\begin{array}{l}\text { Max } \\
\text { Part. } \\
\text { PPP/m }\end{array}$} & \multirow[b]{2}{*}{$\begin{array}{l}\text { Beam } \\
\text { inside } \\
20 \mathrm{~cm} \\
\text { Dia. } \\
\%\end{array}$} & \multirow{2}{*}{ Comments } \\
\hline & $\begin{array}{l}\text { Chicane } \\
\# 2 \\
\% \text { of } \\
2 \mathrm{MW}\end{array}$ & $\begin{array}{l}\text { Chicane } \\
\# 3 \\
\%\end{array}$ & $\begin{array}{l}\text { Chicane } \\
\# 4 \\
\%\end{array}$ & $\begin{array}{l}\text { Dump } \\
\text { Sept } \\
\text { +Quad } \\
\% \text {. of } \\
0.2 \mathrm{MW}\end{array}$ & $\begin{array}{l}\text { Flight } \\
\text { Tube } \\
\%\end{array}$ & & & \\
\hline Ref & $10^{-3}$ & - & - & $4 \times 10^{-2}$ & 0.07 & $2.4 \times 10^{15}$ & 99.8 & Reference Part. Dis. \\
\hline $1 \mathrm{~A}$ & $10^{-3}$ & - & - & $4 \times 10^{-2}$ & 0.40 & $2.49 \times 10^{15}$ & 91.9 & Match Inj. 1x emit \\
\hline $1 \mathrm{~B}$ & $10^{-3}$ & - & - & $4 \times 10^{-2}$ & 2.94 & $1.54 \times 10^{15}$ & 79.8 & Match Inj. $2 x$ emit \\
\hline $1 \mathrm{C}$ & $10^{-3}$ & - & - & 0.17 & 8.85 & $1.47 \times 10^{15}$ & 67.32 & Match Inj. 3x emit \\
\hline $7 \mathrm{~B}$ & $10^{-3}$ & - & - & $4 \times 10^{-2}$ & 0.26 & $3.32 \times 10^{15}$ & 92.9 & Mismatch Inj, 2x emit \\
\hline $9 \mathrm{C}$ & $10^{-3}$ & - & - & 0.15 & 0.54 & $2.45 \times 10^{15}$ & $91.5 \mid \equiv$ & Mismatch Inj. 3x emit \\
\hline
\end{tabular}

\section{Conclusion}

Beam size at the injection dump is acceptable for linac emittance up to three times higher than the nominal emittance with mismatch injection. These calculations do not include the partially chopped beams.

\section{References}

[1] D. Raparia et al, "Beam Dump Optics for SNS", PAC 2003, pp 3417

[2] J. Bebee Wang et al, "Mismatch injection for SNS accumulator ring", SNS Tech Note \# 80, June 1, 2000 

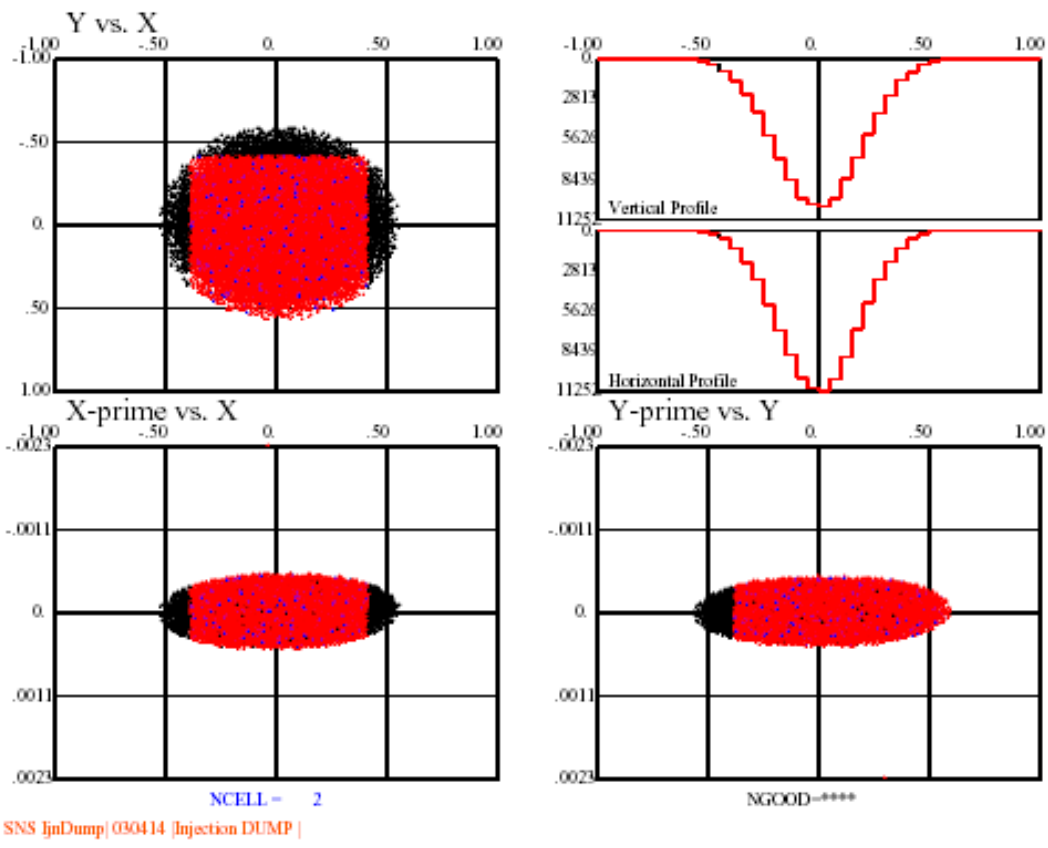

Figure 5A: Reference particle distribution at the foil for the design emittance. Red particles representing $\mathrm{P}, \mathbf{B l a c k} \mathrm{H}^{-}$and $\mathbf{B l u e ~} \mathrm{H}^{0}$.
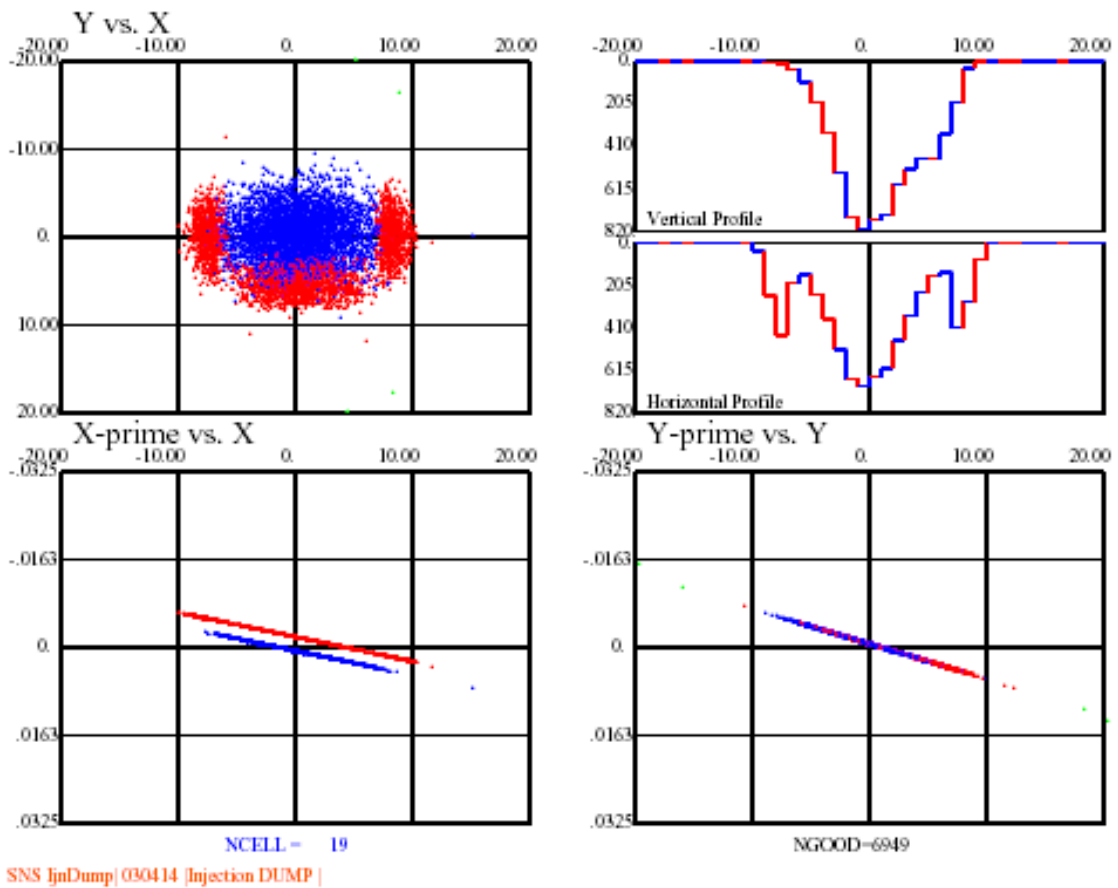

Figure 5B: Reference particle distribution at injection dump for the design emittance (refernce distribution). Red particles representing particle started at foil as $\mathrm{H}^{-}$and Blue $\mathrm{H}^{0}$. 

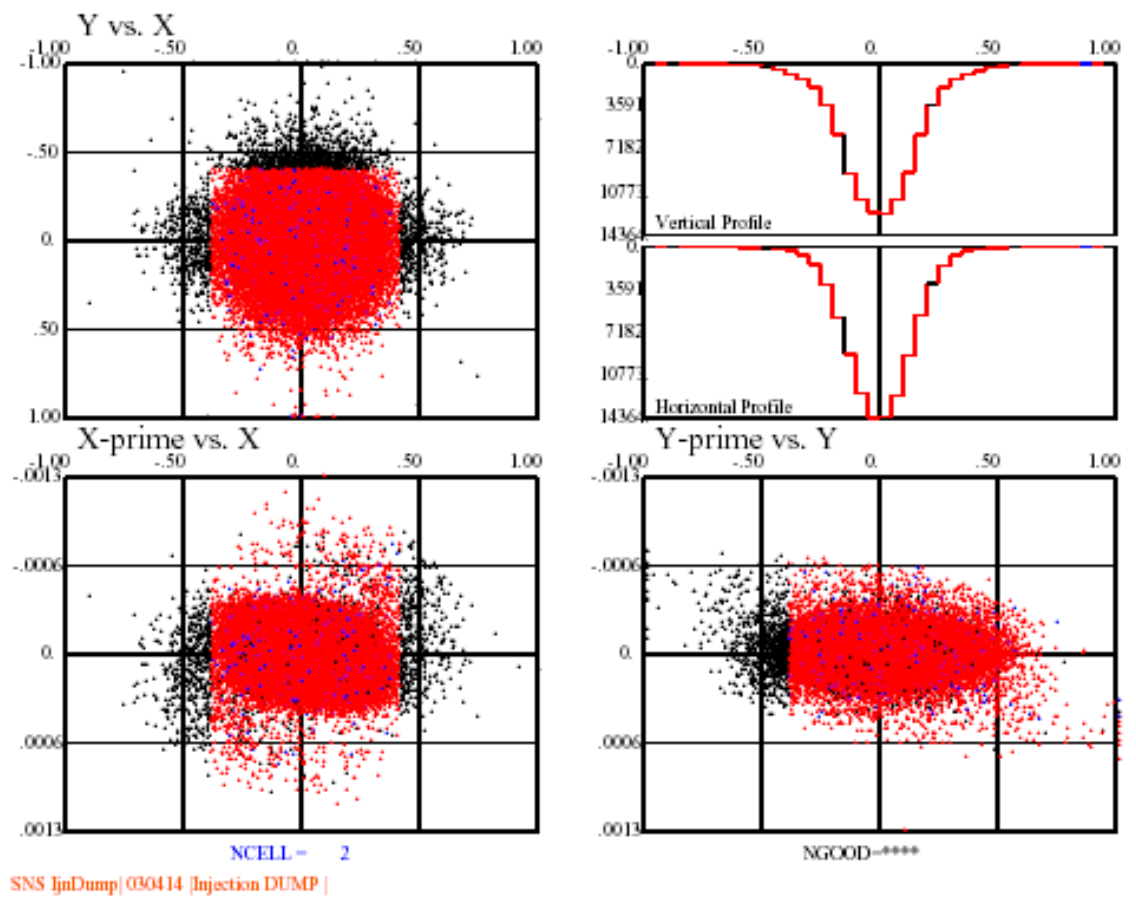

Figure 6A: Particle distribution at the foil for the design emittance. Red particles representing P, Black $\mathrm{H}^{-}$and Blue $\mathrm{H}^{0}$.
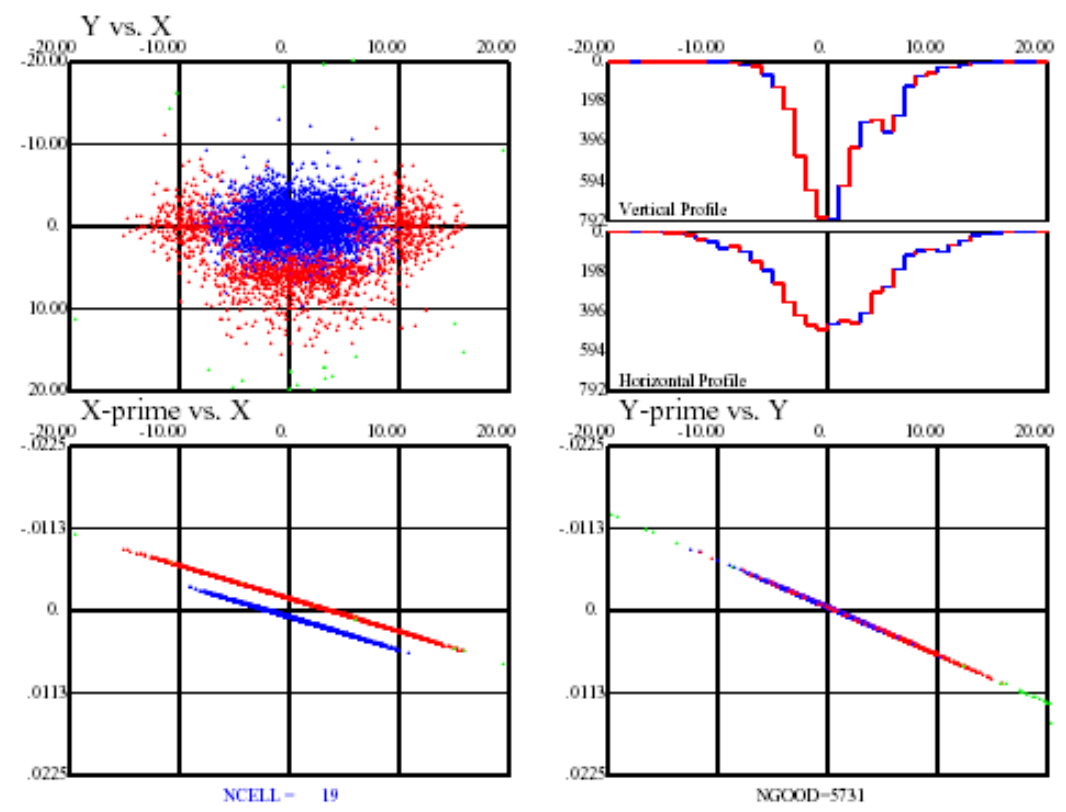

Figure 6B: Particle distribution at Injection Dump for the design emittance. Red particles representing particle started at foil as $\mathrm{H}^{-}$and $\mathrm{Blue}^{0}$. 

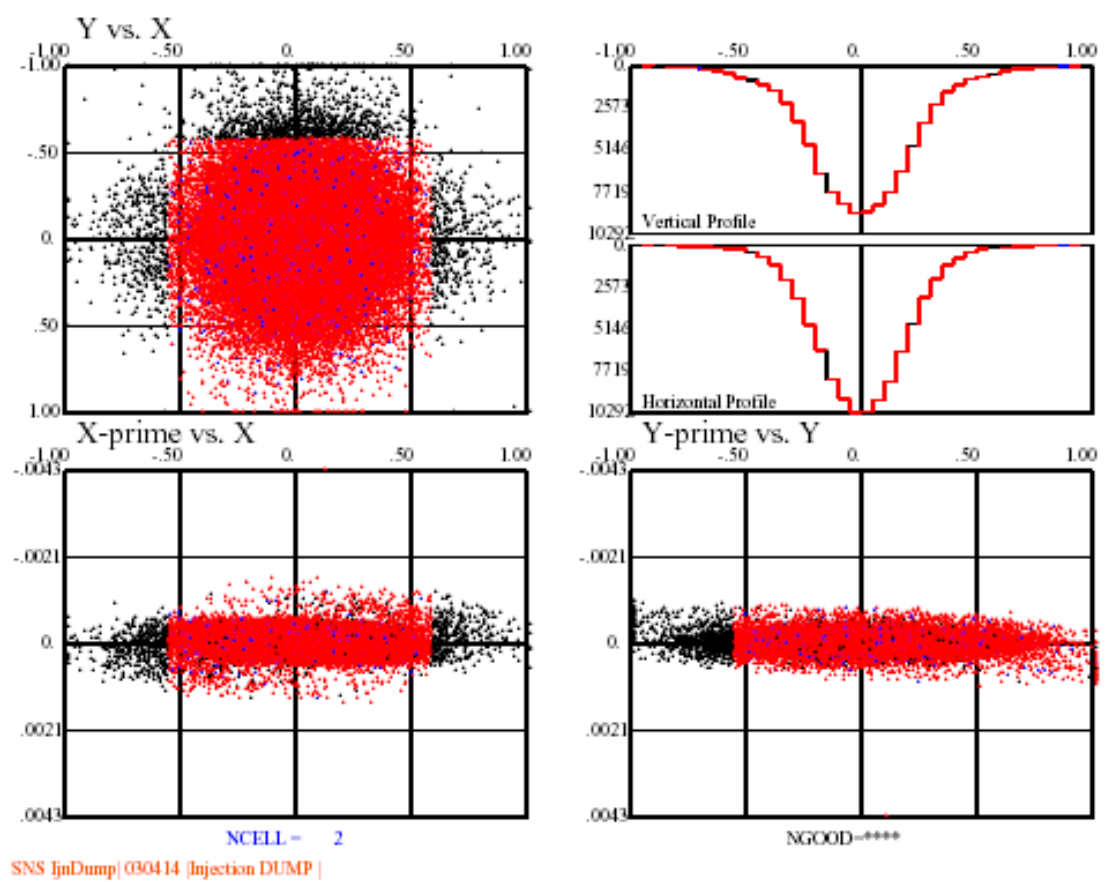

Figure 7A: Particle distribution at the foil for two times the design emittance and matched injection. Red particles representing $\mathrm{P}, \mathbf{B l a c k} \mathrm{H}^{-}$and Blue $\mathrm{H}^{0}$.
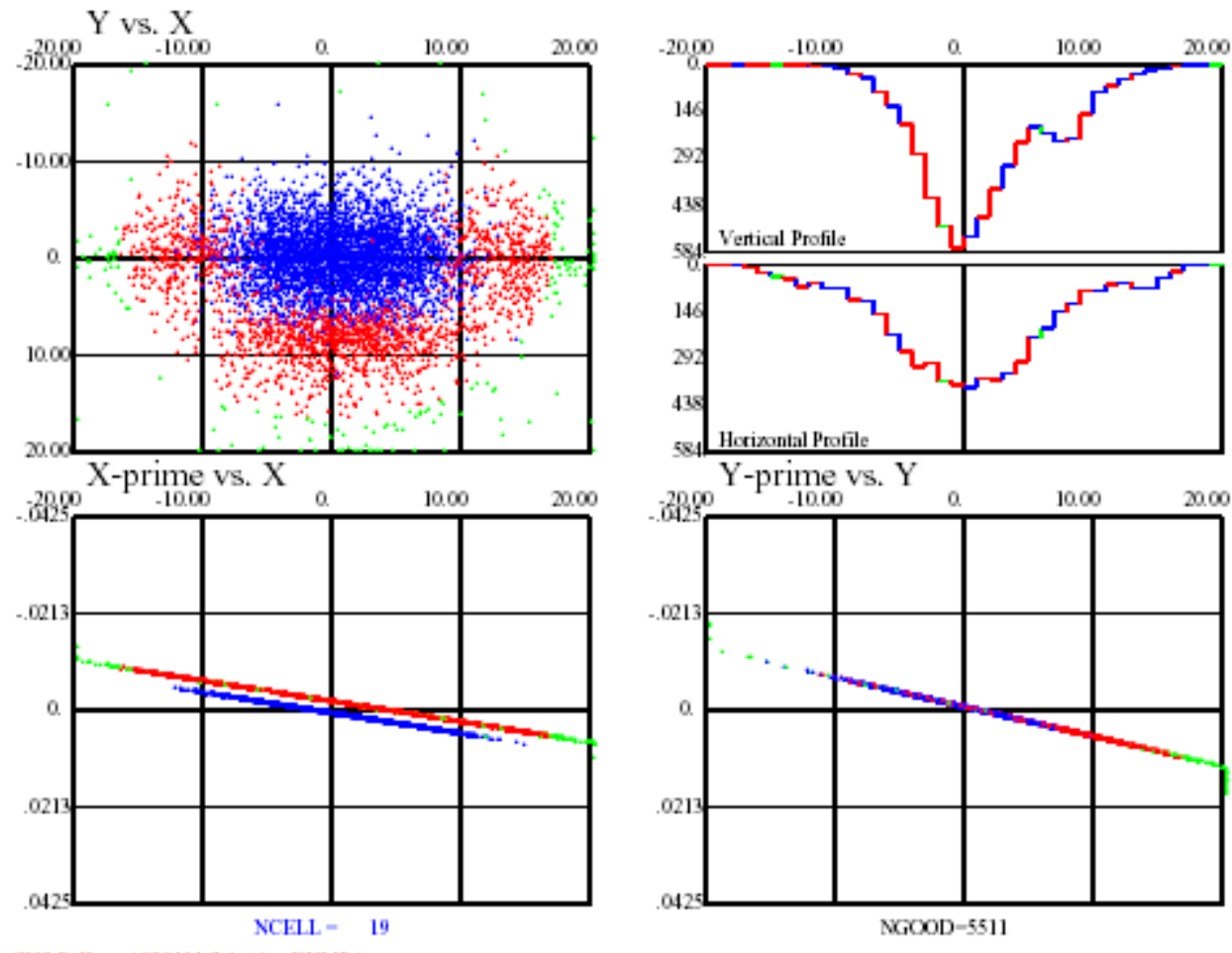

Figure 7B: Particle distribution at Injection Dump for two times the design emittance and matched. Red particles representing particle started at foil as $\mathrm{H}^{-}$, Blue $\mathrm{H}^{0}$ and Green as lost particles in the flight tube. 

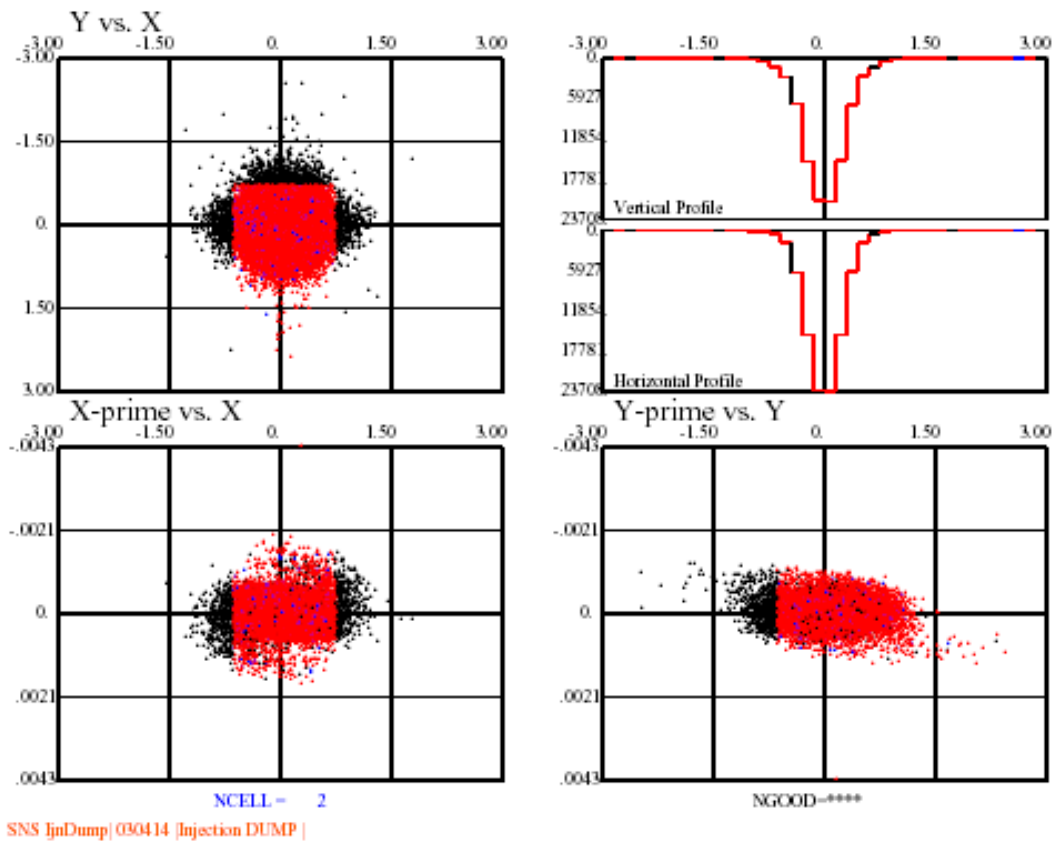

Figure 8A: Particle distribution at the foil for three times the design emittance and matched injection. Red particles representing $\mathrm{P}$, Black $\mathrm{H}^{-}$and Blue $\mathrm{H}^{0}$.
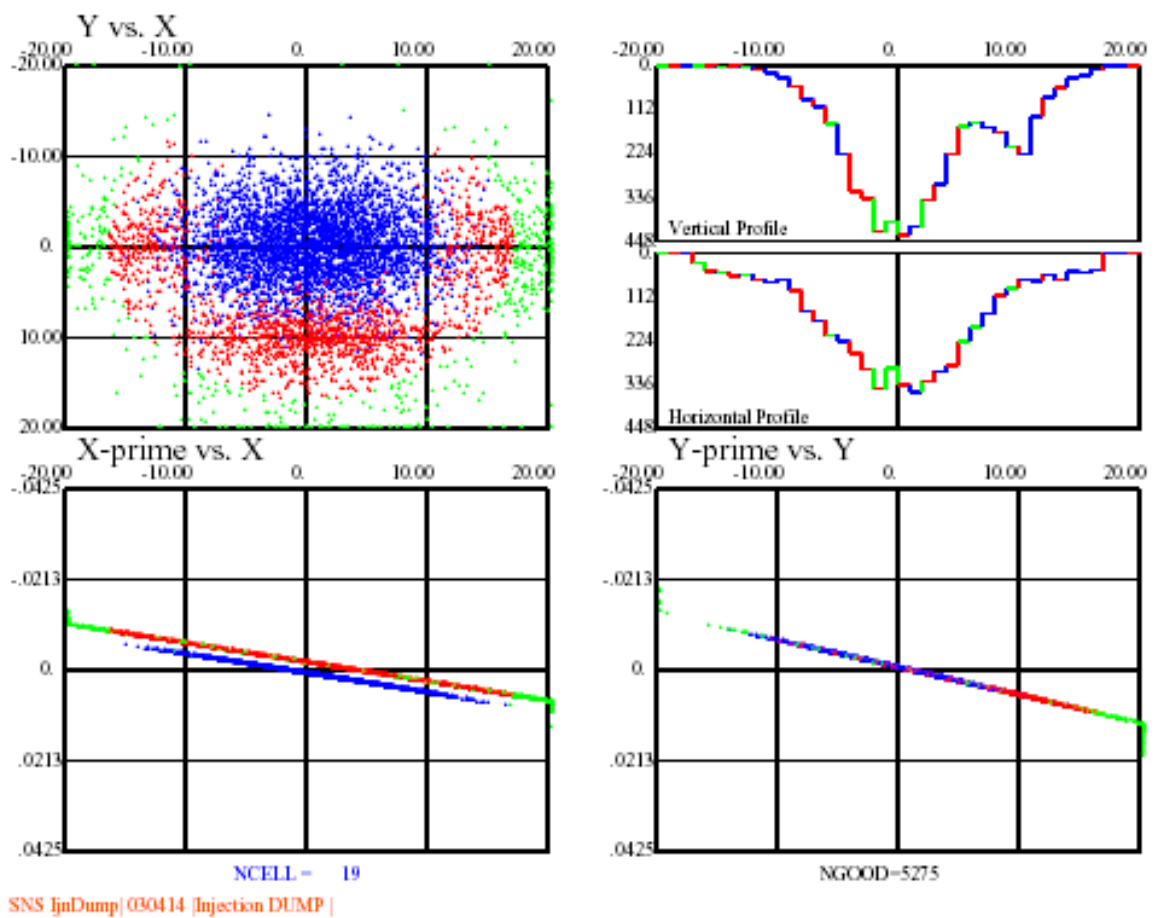

Figure 8B: Particle distribution at Injection Dump for three times the design emittance and matched. Red particles representing particle started at foil as $\mathrm{H}^{-}$, Blue $\mathrm{H}^{0}$ and Green as lost particles in the flight tube. 

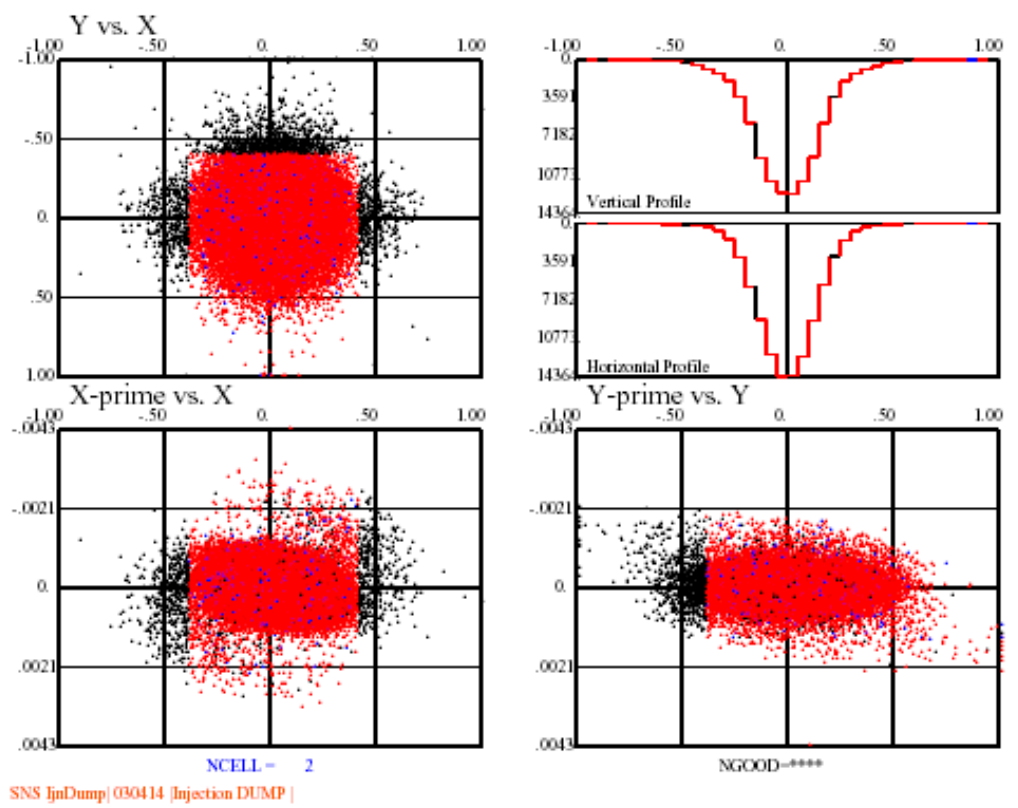

Figure 9A: Particle distribution at the foil for two times the design emittance and mismatched injection. Red particles representing $\mathrm{P}$, Black $\mathrm{H}^{-}$and Blue $\mathrm{H}^{0}$.
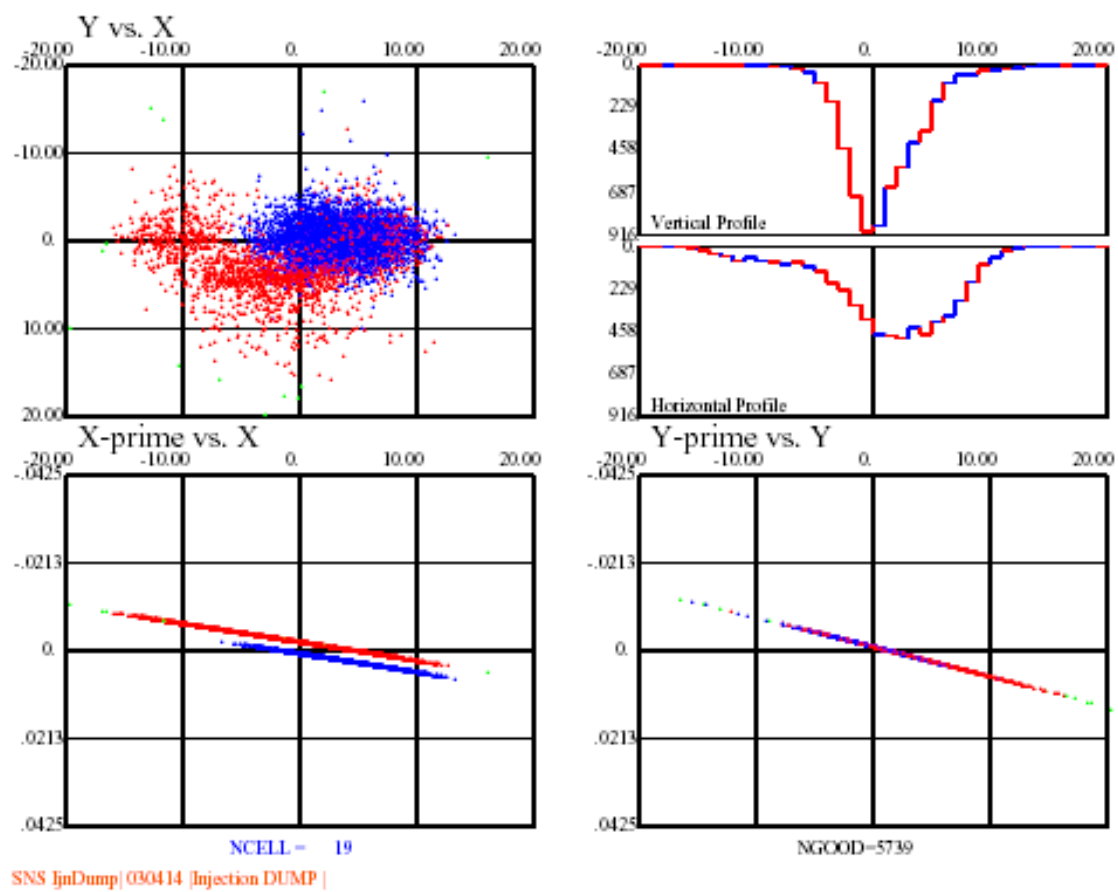

Figure 9B: Particle distribution at Injection Dump for two times the design emittance and mismatched. Red particles representing particle started at foil as $\mathrm{H}^{-}$, Blue $\mathrm{H}^{0}$ and Green as lost particles in the flight tube. 

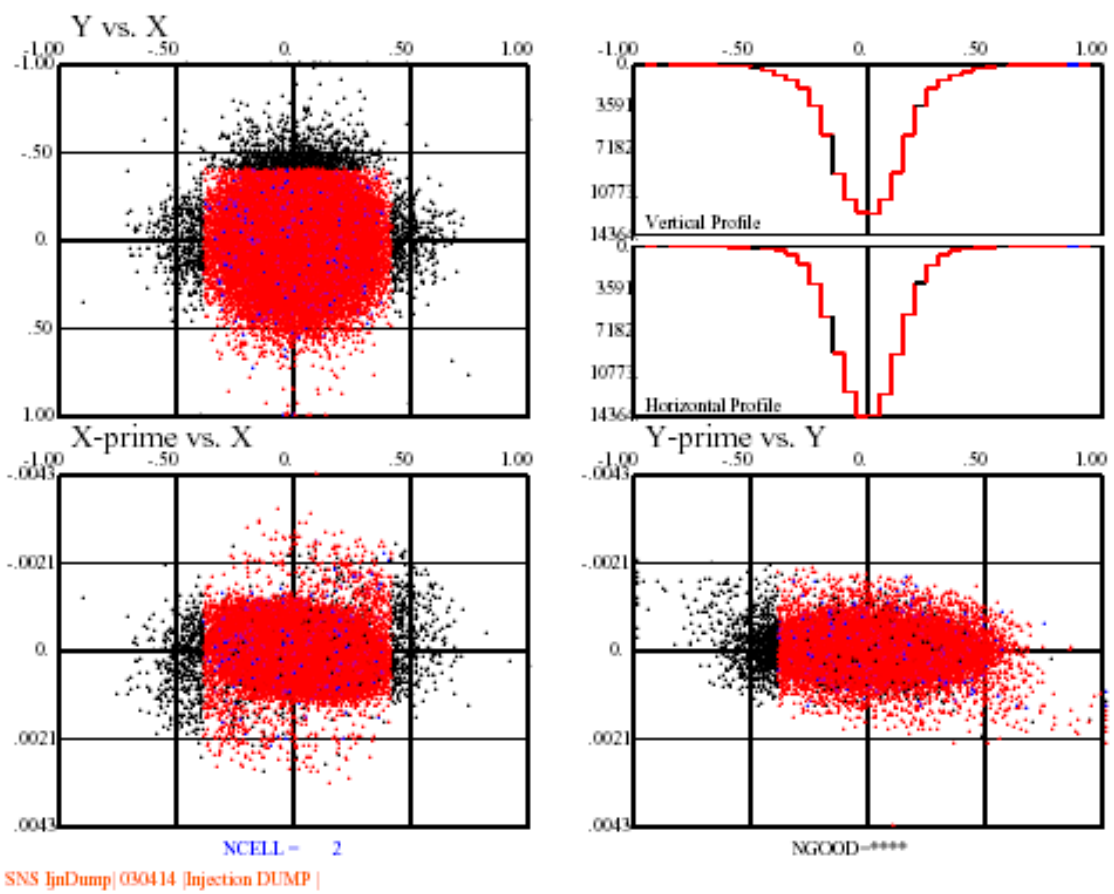

Figure 10A: Particle distribution at the foil for three times the design emittance and mismatched injection. Red particles representing $\mathrm{P}$, Black $\mathrm{H}^{-}$and Blue $\mathrm{H}^{0}$.
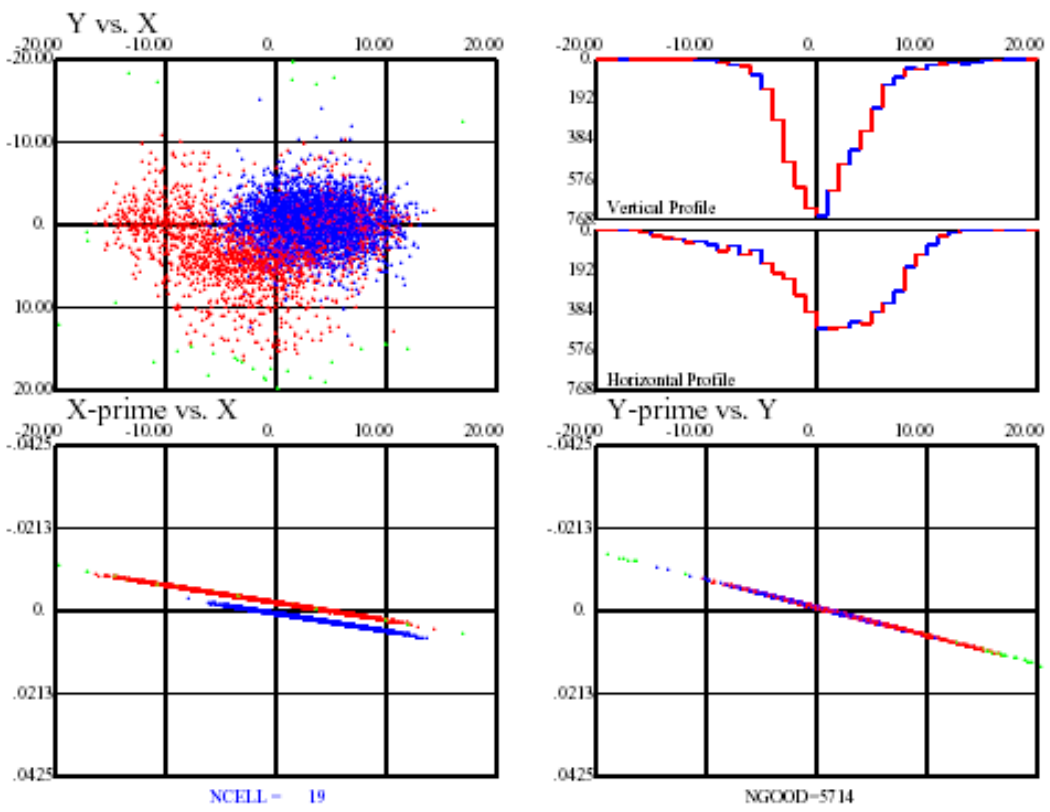

Figure 10B: Particle distribution at Injection Dump for three times the design emittance and mismatched. Red particles representing particle started at foil as $\mathrm{H}^{-}$, Blue $\mathrm{H}^{0}$ and Green as lost particles in the flight tube. 